\title{
True Aneurysm of the Superficial Temporal Artery: Case Report and Review of Literature
}

\author{
Elfatemi B* , Baikal T, Tijani Y, Khloufi S, Sefiani Y, Lekehel B, Mesnaoui A
}

Vascular Surgery Service Ibn Sina Hospital Rabat

DOI: $10.36347 /$ sjmcr.2020.v08i02.037

| Received: 17.02.2020 | Accepted: 24.02.2020 | Published: 27.02.2020

*Corresponding author: Dr. Elfatemi Bouthainah

Abstract

Case Report

Aneurysms of the superficial temporal artery are rare. It can be assumed that their impact is estimated as a result of cases operated but not published. They are mostly atherosclerotic or congenital. Their diagnosis is mainly based on clinical examination and the use of complementary examinations is only indicated for the differential diagnosis or looking aneurysmal other locations. It is necessary to distinguish between true and false aneurysms based on several clinical and pathological features. Few studies have been published in terms of the temporal artery aneurysms in children. Their treatment is surgical and involves the flattening with ligation of the vessel. A case has been reported of a true aneurysm of the superficial temporal artery in a child of 13 years old while recalling the clinical and therapeutic epidemiological characteristics of the disease.

Keywords: True aneurysm - superficially temporal artery - pulsatile mass - rare disease - ligation.

Copyright @ 2020: This is an open-access article distributed under the terms of the Creative Commons Attribution license which permits unrestricted use, distribution, and reproduction in any medium for non-commercial use (NonCommercial, or CC-BY-NC) provided the original author and source are credited.

\section{INTRODUCTION}

Superficial temporal artery pseudo aneurysms (STAPs) are injuries that typically occur after blunt trauma of the temporal artery branch. They are characterized by a localized rupture of the vessel wall and are the most common.

However, "true" aneurysms of the STA are exceptional and are mostly atherosclerotic or congenital $[1,2]$. Very few spontaneous aneurysms of the STA have been reported in the literature. However, the incidence of aneurysms of the STA was, probably, underestimated due to the imprecision of previously published articles and unpublished cases treated [3-9]. In this Article, we report an observation of a true aneurysm of the STA in a 13-year-old child while recalling the clinical and therapeutic particularity of this pathology.

\section{Case Report}

This is a 13-years-old patient with no remarkable pathological history referred for management of two asymptomatic, painless rights and left temporal swellings that had appeared since 4 weeks to 10 weeks apart interval of gradually increasing volume (Figure 1,2). No evidence of trauma or surgery in this area was found during questioning.
On a clinical examination, there were two temporal pulsatile masses; one is on the right side of 2 $\mathrm{cm}$ in diameter and the other one on the left side of 1 $\mathrm{cm}$ in diameter, with abolition of the pulsatile character on compression of the proximal part of the STA. There wasn't any family history of connective tissue disease. Doppler echo revealed the existence of two fusiform aneurysms of $25 \times 15 \mathrm{~mm}$ in diameter on the right side and on the left one of $15 \times 10 \mathrm{~mm}$. The left aneurysm was resected on local anaesthesia, making an incision on the opposite side of the aneurysm, dissecting the temporal artery upstream and downstream of the aneurysmal pocket (Fig. 3, 4) with ligation of the artery on both sides and forwarding the piece to the anatomopathological examination (Fig. 5). The postoperative care was simple. Anatomopathological examination confirmed the presence of the three vascular layers, with ectasia, no obvious signs of inflammation or vasculitis. 


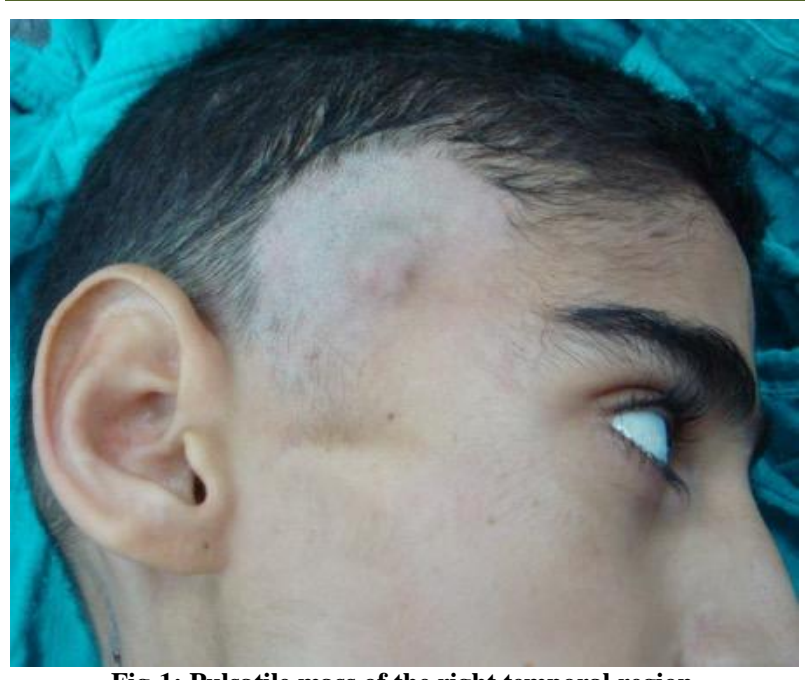

Fig-1: Pulsatile mass of the right temporal region

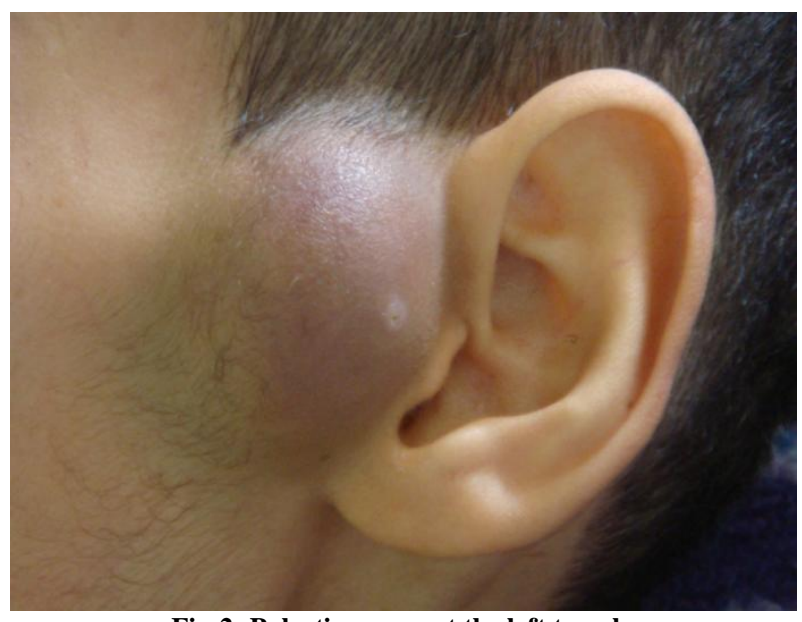

Fig-2: Pulsating mass at the left temple

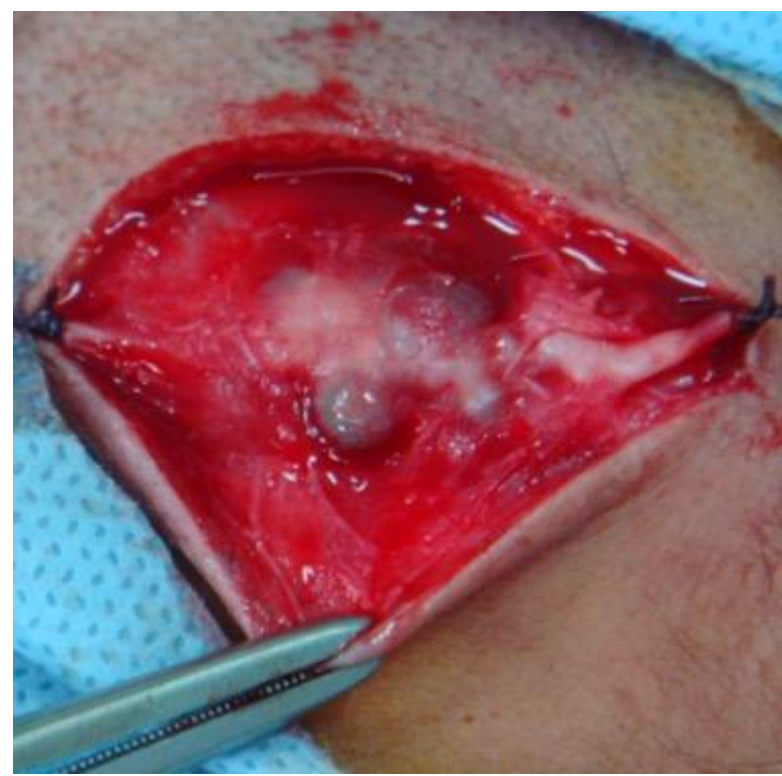

Fig-3: Peroperative picture of the flattening of the left aneurysm of the superficial temporal artery

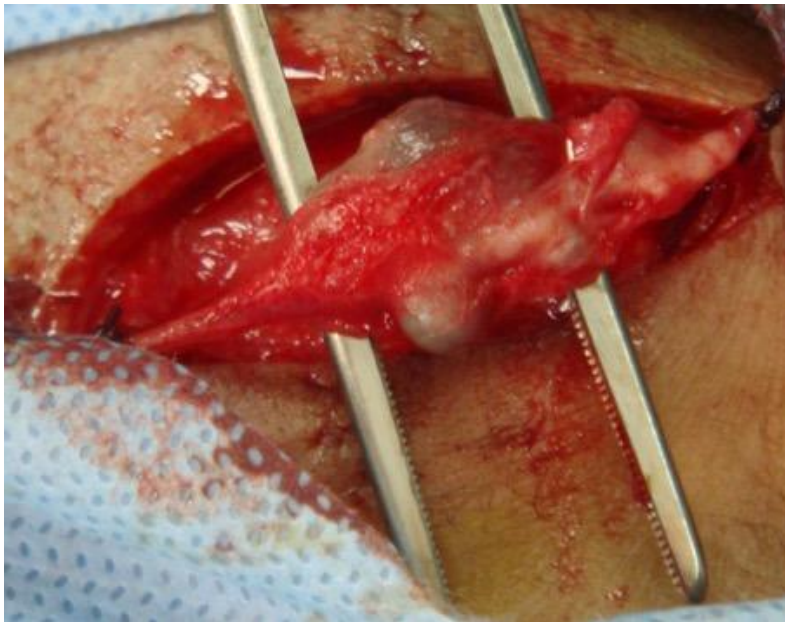

Fig-4: Upstream and downstream control of the aneurysm with ligation of the artery on both sides

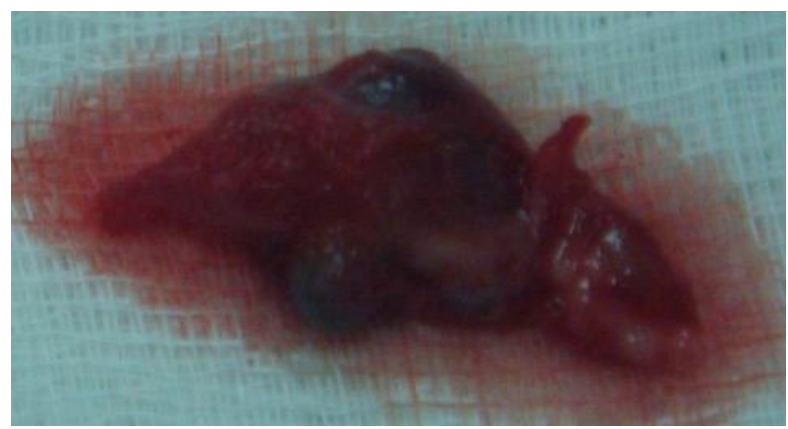

Fig-5: Macroscopic appearance of the aneurysm after resection

\section{DISCUSSION}

Most aneurysms of the STA are actually pseudoaneurysms related to local trauma $[1,2,10]$. "True" aneurysms of the STA are extremely rare. The first cases were reported in 1955 [3], their number did not exceed 20, they were atherosclerotic or congenital [4-9] and often isolated cases. The diagnosis of an aneurysm of the STA is relatively easy, and its management is straightforward and is limited to surgical resection. The first cases described in the literature occurred after vascular wounds (stab wounds, bleeding) [1].

Currently the main etiology is closed trauma of the face and the skull (about $80 \%$ of cases) [1,16]. They occur in the context of brawls (punches, kicks), fall or sports practice $[1,2,15]$. The cause may also be iatrogenic (hair implants, mandibular condyle surgery) $[1,16]$. A case of pseudoaneurysm of the frontal branch of the STA has been described after suprabrow injection of botulinum toxin (BotoxW) [14].

It is a predominantly male affection, mainly before the age of 40 [1]. Paediatric cases have been described [16]. Segment III and the frontal branch of the STA are most often affected, the superficial artery in these two portions $[17,18]$ is more vulnerable $[1,2]$. it is almost always a painless, pulsatile mass $[1,8]$. It usually occurs two to six weeks after the initial trauma 
$[1,12,15]$. In 15 to $20 \%$ of cases, this can range from six months to three years [1].

The diagnosis is suspected in case of pulse abolition and/or decrease in the size of the swelling during arterial compression upstream of the aneurysm $[13,2,15,16]$. While for true aneurysms this compression does not make the aneurysm's pulses disappear. However, true aneurysms of the STA usually present unilaterally, but can also be bilateral;[1,2,6] often without the evidence of trauma as in our patient's case.

Pipinos et al. [2] reported the first observations. In our case the patient presented a bilateral nature, with the appearance of the two aneurysms with 4 weeks apart. It should be noted that no traumatic events were found during medical examination and that there were no other aneurysmal locations.

The disease mainly presented as a pulsatile mass in the temporal region. The main differential diagnoses are: Superficial temporal artery pseudoaneurysms, middle meningeal artery aneurysms with bone destruction (in this case persistence of pulsation after compression of the proximal part of the STA), vascular tumours and arteriovenous malformations $[1,15]$. The subcutaneous nature of the lesion may evoke dermatological lesions: lipomas, sebaceous cysts, epidermal, etc.

The broadest review was reported by Uchida and Sakuma [5], who described 9 cases with an average age of 37.5 years and an average diameter of $18 \mathrm{~mm}$. Riaz et al. [8] described 2 cases of older patients, with a mean age of 71 years. Similarly, Ysa et al. [9] reported the case of a 59-year-old patient.

Generally speaking, interrogation and clinical examination are sufficient to make a positive diagnosis, no further examination is necessary for this clinical presentation [2] However, Doppler echo and CT angiography are performed primarily for the purpose of removing other aneurysmal sites $[9,11]$ and to eliminate other causes of pulsatile tumours.

Histologically, a pseudoaneurysm must be distinguished from aneurysm and angiectasis. In pseudoaneurysm, trauma to the vessel wall causes a breach between the intima and the media with the formation of a hernia communicating with the arterial lumen. The outer side of the vessel is bordered by adventitia or during evolution by fibrous arterial tissue, which can lead to complete destruction of the arterial wall. An aneurysm is a loss of parallelism of the arterial walls due to an alteration of their structure. The three tunics are well identifiable but the media is thinner. Angiectasis is a regular dilatation of the vessel respecting the parallelism and thickness of the vessel wall.

Treatment options for true aneurysms include no surveillance, endovascular embolization, and surgical removal $[1,2,5]$. Although aneurysms of the STA most often have a benign evolution, bleeding is always a concern, along with other potentially disabling symptoms $[2,5]$.

Once the diagnosis has been made, surgical treatment is recommended. Formal indications for surgery are pain, rapid increase in lesion size, aesthetic discomfort, and perilesional skin threat [19]. No formal recommendation has been established taking into account only the size of the lesion $[5,8]$.

Given the richness of the network of collaterals on the face, vascular reconstruction is unnecessary, and simple excision after ligation of the collaterals is the treatment of choice [1-3, 59]. The surgical treatment was performed on local anaesthesia and was relatively simple in our patient. Selective embolization has been suggested as an interesting therapeutic alternative, especially when the lesion is close to the parotid gland and the facial nerve [2, 8]. Embolization has been particularly described in some cases of pseudoaneurysms traumatism of the STA and maxillary artery rather than true aneurysms with complication rates of 1 to $3 \%[1,2]$. Thus, surgery should still be considered the first-line treatment.

\section{CONCLUSION}

True aneurysms of the temporal artery are rare. Their diagnosis is easy and is essentially based on clinical examination. They are mostly atherosclerotic and congenital. Surgery is the treatment of choice.

\section{REFERENCES}

1. Peick AL, Nichols WK, Curtis JJ, Silver D. Aneurysms and pseudoaneurysms of the superficial temporal artery caused by trauma. J Vasc Surg. 1988; 8:606-610.

2. Pipinos, II, Dossa CD, Reddy DJ. Superficial temporal artery aneurysms. J Vasc Surg. 1998; 27:374-377.

3. Martin WL, Shoemaker WC. Temporal artery aneurysm. Am J Surg. 1955; 89:700-702.

4. Cheng CA, Southwick EG, Lewis EC. 2nd. Aneurysms of the superficial temporal artery: literature review and case reports. Ann Plast Surg. 1998; 40:668-671.

5. Uchida N, Sakuma M. Atherosclerotic superficial temporal artery aneurysm: report of a case. Surg Today 1999; 29:575-578.

6. Endo T, Mori K, Maeda M. Multiple arteriosclerotic fusiform aneurysms of the superficial temporal arterydcase report. Neurol Med Chir (Tokyo). 2000; 40:321-323. 
7. Coscar_on Blanco E, Benito JJ, Benito F, G_omez JL, del Can izo Alvarez A, Ant_unez P. Nonpulsatile aneurysm of the superficial temporal artery: a report of a case. Acta Otorrinolaringol. Esp. 2003; 54:388-391.

8. Riaz AA, Ismail $\mathrm{M}$, Sheikh $\mathrm{N}$, et coll. Spontaneously arising superficial temporal artery aneurysms: a report of two cases and review of the literature. Ann R Coll Surg Engl. 2004;86: W38W40.

9. Ysa A, Arruabarrena A, Bustabad MR, Perez E, del Campo A, Garcia Alonso J. Images in vascular medicine. True aneurysm of the superficial temporal artery. Vasc Med. 2008;13: 295-296.

10. Porcellini M, Bernardo B, Spinetti F, Carbone F. Outpatient management of superficial temporal artery aneurysms. J Cardiovasc Surg (Torino). 2001;42:233-236.

11. Locatelli D, Messina AL, Ricevuti G, Gajno TM. Superficial temporal artery aneurysms. J Neuroradiol 1988;15: 89-93.

12. Mann GS, Heran MKS. Percutaneous thrombin embolization of a post-traumatic superficial temporal pseudoaneurysm. Pediatr Radiol. 2007; 37:578-80.
13. Hong JT, Lee SW, Ihn YK, Son BC, Sung JH, Kim IS, Kim IS, Kim MC. Traumatic pseudoaneurysm of the superficial temporal artery treated by endovascular coil embolization. Surgical neurology. 2006 Jul 1;66(1):86-8.

14. Prado A, Fuentes P, Guerra C, Leniz P, Wisnia P. Pseudoaneurysm of the frontal branch of the superficial temporal artery: an unusual complication after injection of botox. Plast Reconstr Surg. 2007; 119:2334-5.

15. De Vogelaere K. Traumatic aneurysm of the superficial temporal artery: case report. J Trauma. 2004; 57:399-401.

16. Quereshy FA, Choi S, Buma B. Traumatic pseudoaneurysm of the superficial temporal artery in a pediatric patient: a case report. J Oral Maxillofac Surg. 2008; 66:133-5.

17. Ricbourg B, Mitz V, Lassau JP. Artère temporale superficielle. Etude anatomique et déductions pratiques. Ann Chi Plast. 1975; 20:197 213.

18. Ricbourg B. Vascularisation cutanée de la faces ET $\mathrm{du}$ cuir chevelu. EMC (Elsevier Masson SAS, Paris), Stomatologie. 2007, 22-001-C-50.

19. Gabriele Piffaretti, Patrizio Castelli, Varese, Anévrysmes de l'artère temporale superficielle: à propos de trois cas. Cas cliniques. 2009; 23(5). 